\title{
Antitumor profiles and cardiac electrophysiological effects of aurora kinase inhibitor ZM447439
}

\author{
Hyang-Ae Lee ${ }^{1}$, Miso Kwon ${ }^{1,2}$, Hyeon-A Kim', and Ki-Suk Kim ${ }^{1, *}$ \\ ${ }^{1}$ R\&D Center for Advanced Pharmaceuticals \& Evaluation, Korea Institute of Toxicology, Korea Research Institute of Chemical Technology, Daejeon 34114, \\ ${ }^{2}$ Fertility Center, CHA Bunding Medical Center, CHA University, Seongnam 13496, Korea
}

\section{ARTICLE INFO \\ Received July 7, 2019 \\ Revised August 8, 2019 \\ Accepted August 8, 2019 \\ *Correspondence \\ Ki-Suk Kim \\ E-mail: idkks@kitox.re.kr}

Key Words

Anticancer agents

Aurora kinases inhibitor

Cardiotoxicity

Efficacy testing

ZM447439
ABSTRACT Aurora kinases inhibitors, including ZM447439 (ZM), which suppress cell division, have attracted a great deal of attention as potential novel anti-cancer drugs. Several recent studies have confirmed the anti-cancer effects of ZM in various cancer cell lines. However, there have been no studies regarding the cardiac safety of this agent. We performed several cytotoxicity, invasion and migration assays to examine the anti-cancer effects of ZM. To evaluate the potential effects of ZM on cardiac repolarisation, whole-cell patch-clamp experiments were performed with human induced pluripotent stem cell-derived cardiomyocytes (hiPSC-CMs) and cells with heterogeneous cardiac ion channel expression. We also conducted a contractility assay with rat ventricular myocytes to determine the effects of ZM on myocardial contraction and/or relaxation. In tests to determine in vitro efficacy, ZM inhibited the proliferation of A549, H1299 (lung cancer), MCF-7 (breast cancer) and HepG2 (hepatoma) cell lines with $\mathrm{IC}_{50}$ in the submicromolar range, and attenuated the invasive and metastatic capacity of A549 cells. In cardiac toxicity testing, ZM did not significantly affect $I_{\mathrm{Na}}, I_{\mathrm{KS}}$ or $I_{\mathrm{K} 1}$, but decreased $I_{\text {hERG }}$ in a dose-dependent manner $\left(\mathrm{IC}_{50}: 6.53\right.$ $\mu \mathrm{M})$. In action potential (AP) assay using hiPSC-CMs, ZM did not induce any changes in AP parameters up to $3 \mu \mathrm{M}$, but it at $10 \mu \mathrm{M}$ induced prolongation of AP duration. In summary, ZM showed potent broad-spectrum anti-tumor activity, but relatively low levels of cardiac side effects compared to the effective doses to tumor. Therefore, ZM has a potential to be a candidate as an anti-cancer with low cardiac toxicity.

\section{INTRODUCTION}

A number of studies have shown that aurora kinase (AK) overexpression and amplification are closely related to various human cancers [1-4]. AKs participate in mitotic events and influence essential processes in human carcinogenesis, telomerase activity, collagen I-induced cell migration and anchorage-independent growth [3]. Therefore, there has been a great deal of research interest in the development of potential $\mathrm{AK}$ inhibitors [5]. Three members of the AK family, Aurora-A, Aurora-B, and Aurora-C, are associated with multiple aspects of mitosis. Aurora-A localizes to centrosomes/spindle poles and is required for spindle assembly, whereas Aurora B is a chromosome passenger protein required for phosphorylation of histone $\mathrm{H} 3$, chromosome segregation, and cytokinesis. Aurora-A and Aurora-B are frequently overexpressed in a variety of tumors in humans and promote cell cycle progression. Although Aurora-A has attracted the most attention with regard to the link with human cancer, Aurora-B may be a more suitable anti-cancer drug target because inhibition of Aurora-B rapidly results in mitotic arrest and cell death. Aurora- $C$ may rescue the Aurora B-silenced multinucleation phenotype in human cells because it shows functional overlap with Aurora-B [6,7].

ZM447439 (ZM) is a potent and selective inhibitor of Aurora A and $\mathrm{B}$ kinases, with similar $50 \%$ inhibitory concentrations $\left(\mathrm{IC}_{50}\right)$

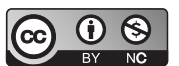

This is an Open Access article distributed under the terms of the Creative Commons Attribution Non-Commercial License, which permits unrestricted non-commercial use, distribution, and reproduction in any medium, provided the original work is properly cited. Copyright @ Korean J Physiol Pharmacol, pISSN 1226-4512, elSSN 2093-3827
Author contributions: H.A.L. and K.S.K. conceived and designed the experiments. H.A.L., M.K., and H.A.K. performed the experiments. H.A.L. and M.A.K. analyzed the data. H.A.L. and M.K. wrote the paper. H.A.L. and K.S.K. supervised the project. 
seen for both kinases [8]. Aurora kinase inhibitors (AKIs), including daurinol, alisertib, and TC-A2317, were shown to induce apoptosis in vitro and in vivo [9-11]. In 2010, Li et al. [12] reported that ZM-induced apoptosis was associated with the upregulation of p53, breakdown of the mitochondrial membranes and activation of caspase-3.

The development of newer targeted anti-cancer agents, including some kinase inhibitors, has increased the life expectancy of patients with several types of cancer. However, a number of drugs used in oncology can affect the heart in various ways [1317]. Cardiotoxicity covers a wide range of side effects, including arrhythmias, especially torsades de pointes induced by QT-prolonging drugs, and dysfunction of myocardial contraction and/ or relaxation [18]. Therefore, it is necessary to verify the cardiac safety of novel anti-cancer drugs. Several recent studies have confirmed the anti-cancer effects of ZM in various cancer cell lines. However, there have been no studies regarding the cardiac safety of ZM using electrophysiological tools and image-based contractility assays. In this study, we demonstrated the potential effects of ZM on cardiac repolarisation using a whole-cell patch-clamp technique with human induced pluripotent stem cell-derived cardiomyocytes (hiPSC-CMs). The hiPSC-CMs are a potentially ideal source of human cardiomyocytes (CMs) for pharmacological screening, with no associated ethical issues and no differences among species. We also analyzed the mechanism of action of ZM using cells with heterogeneous cardiac ion channel expression. Furthermore, we performed image-based contractility assays with enzymatically isolated rat ventricular myocytes to determine the effects of ZM on myocardial contraction/relaxation. This approach improved our understanding of the potential mechanism underlying ZM-induced cardiotoxicity and provided insight into the usefulness of hiPSC-CMs as a new human model for assessing the safety of AKI-related drugs.

\section{METHODS}

\section{Animals}

Contractility assay using the left ventricular myocytes was performed using Sprague-Dawley rats (female, 250-350 g). The animals were kept in a storage room under standard conditions of constant temperature $\left(23 \pm 1^{\circ} \mathrm{C}\right)$, relative humidity $(50 \pm 10 \%)$ and illumination ( $12 \mathrm{~h}$ light/dark cycles) until initiation of the experiment. These studies were conducted in facilities approved by the Association for Assessment and Accreditation of Laboratory Animal Care International. All procedures were approved by the Institutional Animal Care and Use Committee (IACUC) at the Korea Institute of Toxicology (IACUC approval No. RS13006).

\section{Drug and solutions}

ZM was purchased from Toronto Research Chemicals (North York, ON, Canada) and it was formulated into a stock solution with dimethyl sulfoxide (DMSO). The stock solution was further diluted in the bath solution to yield final perfusion solutions with $0.1 \%$ DMSO and appropriate drug concentrations. All chemicals for solution preparation were purchased from Sigma-Aldrich Co. (Sigma-Aldrich, St. Louis, MO, USA).

\section{Cell culture and transfection for ion channel studies}

The hiPSC-CMs (Cardiosight-S; NEXEL, Co., Ltd., Seoul, Korea) were used for single-cell action potential assay. The cells were cultured according to the manufacturer's instructions. To recording of cardiac APs using a patch-clamp system, the cells were cultured to four-well plates containing Matrigel (Corning, Cat. \# 354234)-coated glass coverslips at a low density to yield single uncoupled cells. The cells maintained in a culture incubator at $37^{\circ} \mathrm{C}$ in an atmosphere of $95 \%$ air and $5 \% \mathrm{CO}_{2}$ and used within 4 weeks after thawing.

For various aspects of cardiac ion channel study, human embryonic kidney (HEK293; ATCC, Manassas, VA, USA) cells were transiently transfected using lipofectAmin2000 (Gibco BRL, New York, NY, USA) according to the manufacturer's instructions. The hERG (human ether-ago-go-related gene corresponding to $I_{\mathrm{Kr}}$ ), KCNQ1/KCNE1 (the gene corresponding to $I_{\mathrm{Ks}}$ ), KCNJ2 (the gene corresponding to $I_{\mathrm{K} 1}$ ) or SCN5A (the gene corresponding to $\left.I_{\mathrm{Na}}\right)$ cDNA was co-transfected with green fluorescence protein, the surface marker protein, to allow assessment of the transfection efficiency. For the calcium current, a $\mathrm{Ca}_{\mathrm{v}} 1.2$-expressing cell line (human $\mathrm{Ca}_{\mathrm{v}} 1.2 / \beta 2 / \alpha 2 \delta 1$ calcium channel cell line, Cat. \#CT6004) was purchased from Charles River (Cleveland, OH, USA).

\section{Whole-cell voltage-clamp recordings}

The external solution for recording the $I_{\mathrm{hERG}}, I_{\mathrm{Ks}}$ and $I_{\mathrm{Na}}$ channel currents was normal Tyrode's solution. The internal solution for $I_{\text {hERG }}$ contained the following (in $\mathrm{mM}$ ): $130 \mathrm{KCl}, 5$ ethylene glycol bis(2-aminoethylether)- $N, N, N^{\prime}, N^{\prime}$-tetraacetic acid (EGTA), 10 $N$-(2-hydroxyethyl)piperazine- $N$ '-2-ethansulfonic acid (HEPES), $1 \mathrm{MgCl}_{2}, 5 \mathrm{Mg}$-ATP (pH 7.25 with $\mathrm{KOH}$ ), and for $I_{\mathrm{Ks}}$ in the KCNQ1/KCNE1-cotransfected HEK293 cells, $150 \mathrm{KCl}, 5$ EGTA, 10 HEPES, $2 \mathrm{MgCl}_{2}, 1 \mathrm{CaCl}_{2}$ and $5 \mathrm{Na}_{2}$-ATP (pH adjusted 7.25 with $\mathrm{KOH}$ ). The internal solution for $I_{\mathrm{K} 1}$ in KCNJ2-transfected HEK293 cells contained (in mM): $130 \mathrm{~K}-\mathrm{Asp}, 15 \mathrm{KCl}, 10 \mathrm{HEPES}$, $1 \mathrm{MgCl}_{2}, 5 \mathrm{Na}_{2}$-ATP, 5 EGTA (pH 7.25 with $\mathrm{KOH}$ ), and for the sodium current in SCN5A-transfected HEK293 cells, 105 CsF, 35 $\mathrm{NaCl}, 10$ EGTA, 10 HEPES (pH 7.25 with $\mathrm{NaOH}$ ). The calcium current was measured in a $\mathrm{Ca}_{\mathrm{v}} 1.2$-expressing $\mathrm{CHO}$ cell line, the cells were superfused with an external solution that consisted of (in 
mM): $145 \mathrm{NaCl}, 5.4 \mathrm{KCl}, 10$ HEPES, $1 \mathrm{MgCl}_{2}, 5$ glucose, $1.8 \mathrm{CaCl}_{2}$ $(\mathrm{pH} 7.4$ with $\mathrm{NaOH}$ ), whereas the intracellular solution used to fill the pipette had the following ionic solution (in $\mathrm{mM}$ ): $20 \mathrm{CsCl}$, 120 Cs-aspartate, $5 \mathrm{NaCl}, 10 \mathrm{EGTA}, 10 \mathrm{HEPES}, 20 \mathrm{TEA}-\mathrm{Cl}, 5 \mathrm{Mg}$ ATP (pH 7.25 with $\mathrm{CsOH})$.

\section{Cell viability assay (MTS assay)}

A549 (human lung carcinoma cell line; ATCC CCL-185), HepG2 (human liver cancer cell line; ATCC HB-8065), MCF7 (human breast cancer cell line; ATCC HTB-22), NCI-H1299 (human non-small cell lung carcinoma cell line, ATCC CRL5803) and human lung fibroblast (HLF; ATCC PCS-201-013) cells were plated $\left(1 \times 10^{3}\right.$ cells $)$ in 96 -well plates in basal medium (10\% foetal bovine serum [FBS] in Dulbecco's modified Eagle's medium [DMEM]). After $24 \mathrm{~h}$, the medium was replaced with serum-free DMEM. At the same time, cells were treated with $\mathrm{ZM}$ at various concentrations $(0.01,0.03,0.1,1,3$, and $10 \mu \mathrm{M})$. After 24, 48, and $72 \mathrm{~h}$, each well was treated with $20 \mu \mathrm{l}$ of the tetrazolium compound 3-(4,5-dimethylthiazol-2-yl)-5-(3carboxymethoxyphenyl)-2-(4-sulfophenyl)-2H-tetrazolium (MTS; Promega, Madison, WI, USA) for $2 \mathrm{~h}$ in a $37^{\circ} \mathrm{C}$ incubator. Optical density was then read directly at $492 \mathrm{~nm}$ using a SpectraMax M3 plate reader (Molecular Devices LLC, San Jose, CA, USA).

\section{Invasion assay}

A549 cells were plated $\left(1 \times 10^{6}\right.$ cells $)$ on 10 -cm cell culture dishes in basal medium (10\% FBS in DMEM). After $24 \mathrm{~h}$, the medium was replaced with serum-free DMEM. At the same time, cells were treated with ZM at a concentration of $100 \mathrm{nM}, 1 \mu \mathrm{M}$ or $10 \mu \mathrm{M}$ in individual plates. After 24, 48, and $72 \mathrm{~h}$, A549 cells were reseeded $\left(6 \times 10^{4}\right.$ cells) in Matrigel and fibronectin (BD Biosciences, San Jose, CA, USA)-coated Falcon cell culture inserts with a basal medium. The invasion assay was carried out for $24 \mathrm{~h}$ in a tissue culture incubator. After $24 \mathrm{~h}$, the cells were fixed with $4 \%$ formaldehyde dissolved in phosphate-buffered saline (PBS; Santa Cruz Biotechnology, Inc., Dallas, TX, USA). After fixing for 1 $\mathrm{min}$, the chambers were rinsed once in PBS and then stained with hematoxylin and eosin (Merck, Mendota Heights, MN, USA) for 3-5 min. These cells were counted under a microscope with a $4 \times$ objective.

\section{Migration assay (wound healing assay)}

A549 cells were plated on $10-\mathrm{cm}$ cell culture dishes in basal medium (10\% FBS in DMEM). The next day, the media were replaced with serum-free DMEM and cells were treated with $3 \mu \mathrm{M}$ $\mathrm{ZM}$ for $72 \mathrm{~h}$. A549 cells were then reseeded at $10^{5}$ cells per well in 48 -well plates. After $24 \mathrm{~h}$, wounds were made in each well and the medium was replaced with fresh medium. The wounds were observed under a microscope with a $4 \times$ objective.

\section{Myocyte contractility assay}

To study the effect of ZM on myocytes contractility, we isolated single rat ventricular myocytes (rVMs) using the Langendorff system. Rats were anesthetized with pentobarbital sodium $(30 \mathrm{mg} /$ $\mathrm{kg}$, i.p.), and the hearts were extracted and rapidly mounted onto the Langendorff perfusion system which were then perfused with $\mathrm{a} \mathrm{Ca}^{2+}$-free solution for $10 \mathrm{~min}$ (in $\mathrm{mM} ; \mathrm{NaCl} 135, \mathrm{KCl} 5.4, \mathrm{MgCl}_{2}$ 3.5, glucose 5, HEPES 5, $\mathrm{Na}_{2} \mathrm{HPO}_{4} 0.4$, taurine 20 at $\mathrm{pH}$ of 7.4, $\mathrm{NaOH}$ ), followed by a further 8-min perfusion with the same solution containing collagenase $(1 \mathrm{mg} / \mathrm{ml}$, Worthington Biochemical Co.; protease, $0.133 \mathrm{mg} / \mathrm{ml}$, BSA $1.65 \mathrm{mg} / \mathrm{ml} ; \mathrm{Ca}^{2+} 0.05 \mathrm{mM}$ ). Afterward, the LV free wall was dissected and incubated in a fresh collagenase-only solution. The rVMs were harvested following a further 10-min digestion period, washed and resuspended in storage solution (in mM; $\mathrm{NaCl} 120, \mathrm{KCl} 5.4, \mathrm{MgSO}_{4} 5, \mathrm{CaCl}_{2}$ 0.2 , Na-pyruvate 5 , glucose 5.5 , taurine 20 , HEPES 10 , mannitol $29, \mathrm{pH} 7.4, \mathrm{NaOH})$. The myocyte suspension was stored at room temperature and cells were used within $8 \mathrm{~h}$ of isolation. Changes in sarcomere length were measured in LV myocytes by using a video-sarcomere detection system (IonOptix Corp., Milton, MA, USA). All experiments were carried out at $36 \pm 1^{\circ} \mathrm{C}$ and paced at a frequency of $2 \mathrm{~Hz}$. Measurements from at least 10 steady-state contractions were averaged for each myocyte and for each stage of the experimental protocols. Data analysis was performed offline using IonWizard software (IonOptix Corp.). Sarcomere waveforms were collected and analyzed at baseline and at each testing concentration.

\section{Statistical analysis}

pCLAMP (Axon Instruments, Foster City, CA, USA), Origin 8 (OriginLab Corp, Northampton, MA, USA), Excel (Microsoft, Redmond, WA, USA), and GraphPad Prism (GraphPad Software, San Diego, CA, USA) were used for data acquisition and analysis. The concentration-response relationships for drug-induced blockage were calculated using SigmaPlot (Systat Software, San Jose, CA, USA). The $\mathrm{IC}_{50}$ values, the drug concentration that reduced the ionic currents by $50 \%$, were obtained using the sigmoidal Hill equation: $\mathrm{f}=\mathrm{x}^{\mathrm{H}} /\left(\mathrm{IC}_{50}{ }^{\mathrm{H}}+\mathrm{x}^{\mathrm{H}}\right)$, where $\mathrm{x}$ is the concentration, $\mathrm{H}$ is the Hill coefficient, and $\mathrm{f}$ is the inhibition ratio. Data are presented as the means \pm standard error of the mean (SEM) or standard deviation, and $\mathrm{n}$ represents the number of experimental replicates. Statistical significance was determined using the Student's t-test and one-way ANOVA with post hoc testing using Dunnett's method; $\mathrm{p}<0.05$ was considered to indicate statistical significance. 


\section{RESULTS}

\section{Inhibitory effects of ZM on cancer cell viability}

The MTS in vitro cell proliferation assay is one of the most widely used assays for evaluating preliminary anticancer activity.
To assess the in vitro anticancer activity of ZM, MTS assays were performed with various cancer cell lines-A549 (non-small cell lung cancer), MCF-7 (breast cancer), NCI-H1299 (non-small cell lung cancer), HepG2 (human hepatocellular carcinoma) and HLF cells-after treatment with ZM at several concentrations (0.01, $0.03,0.1,1,3$, and $10 \mu \mathrm{M})$. After 24,48 , or $72 \mathrm{~h}$ of incubation, cell
A

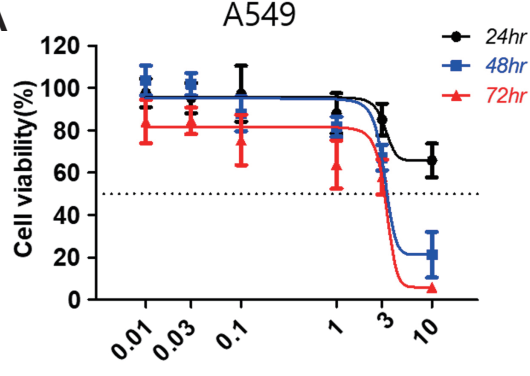

Concentration $(\mu \mathrm{M})$
B

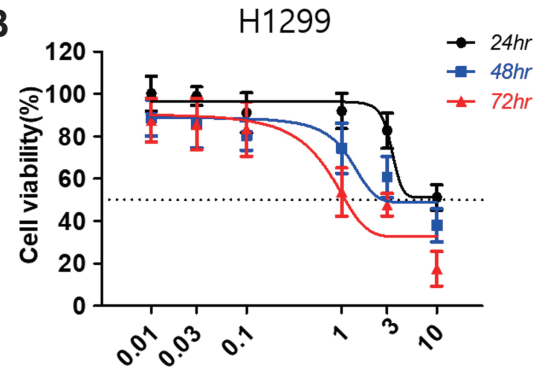

Concentration $(\mu \mathrm{M})$

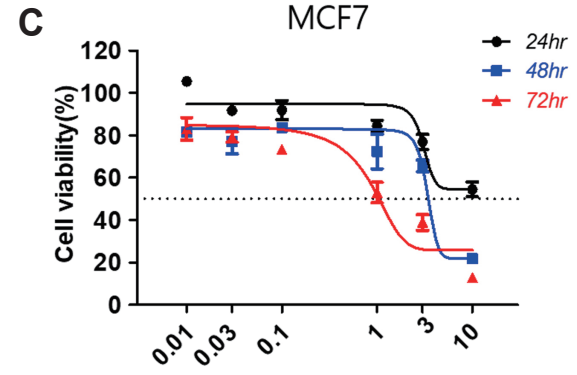

Concentration $(\mu \mathrm{M})$
D

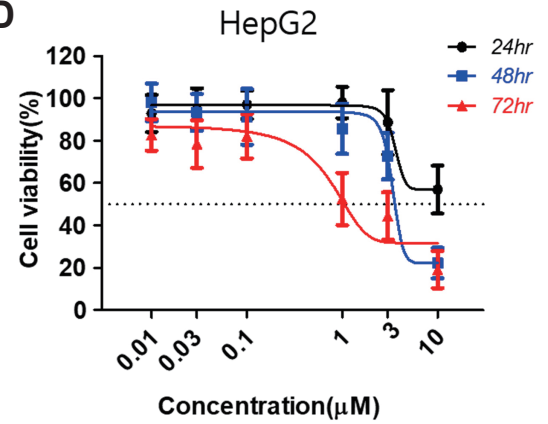

E

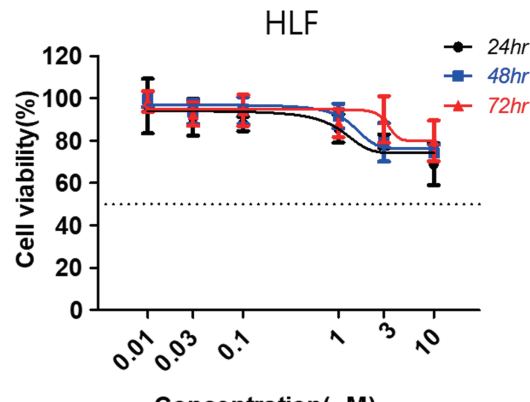

Fig. 1. Cytotoxicity of ZM447439 (ZM) on human cancer cell lines and normal lung fibroblast. 3-(4,5-dimethylthiazol-2-yl)-5-(3carboxymethoxyphenyl)-2-(4-sulfophenyl)-2H-tetrazolium (MTS) assays were performed with various cancer cell lines-(A) A549 (non-small cell lung cancer), (B) MCF-7 (breast cancer), (C) NCI-H1299 (non-small cell lung cancer), (D) HepG2 (human hepatocellular carcinoma) and (E) HLF (human lung fibroblast) cells-after treatment with ZM at several concentrations $(0.01,0.03,0.1,1,3$, and $10 \mu \mathrm{M})$. After 24, 48 or $72 \mathrm{~h}$ of incubation, cell viability was examined by MTS assay. Data are presented as mean \pm standard deviation $(n=3)$.

A

VC

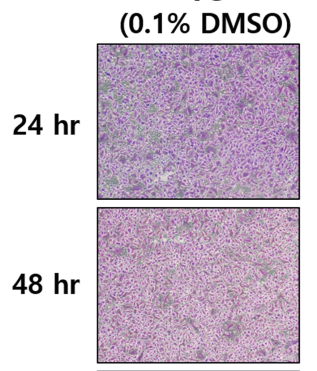

$72 \mathrm{hr}$

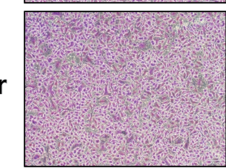

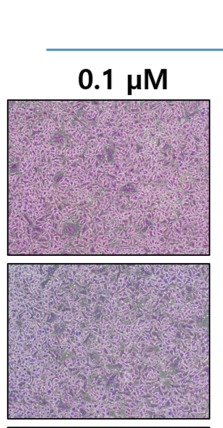

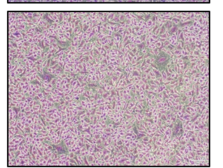

ZM
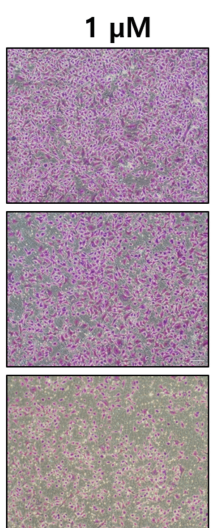

B

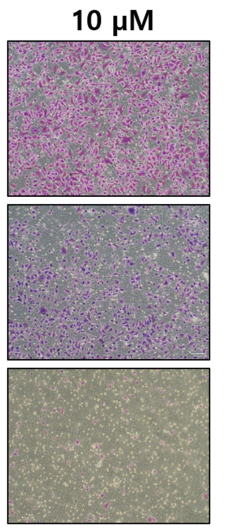

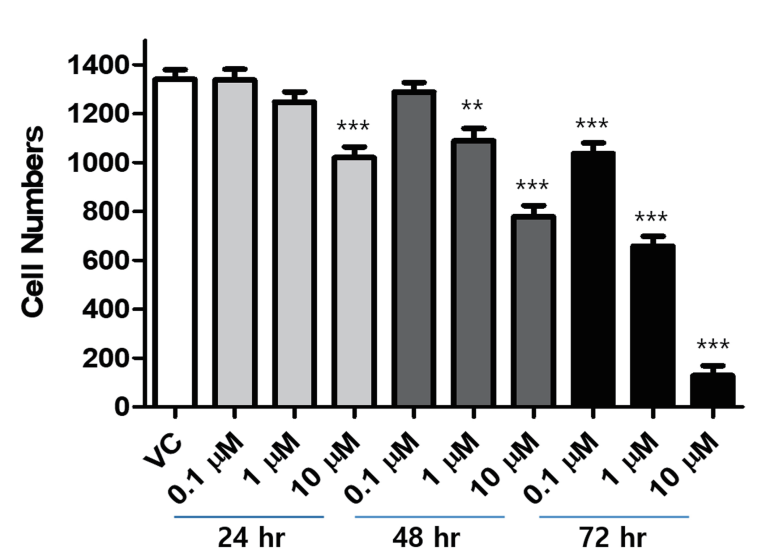

Fig. 2. Invasion assay on ZM447439 (ZM) treated A549 cells. (A) Representative images of the invasiveness of A549 cells that migrated through transwell membranes. Cells were treated with $0.1,1$, and $10 \mu \mathrm{M}$ ZM for 24,48 , and $72 \mathrm{~h}$. (B) Quantification of the transwell assay by counting the number of invasive cells through the transwell membranes. Data are presented as mean \pm standard deviation and compared by ANOVA followed by Dunnett's test (each $n=3$ ). ${ }^{* *} p<0.01 ;{ }^{* * *} p<0.001$, compared with vehicle control (VC, $0.1 \%$ dimethyl sulfoxide [DMSO] treated cells). 
viability was examined by MTS assay. ZM showed concentrationand time-dependent cytotoxicity in all cancer cell lines but the inhibitory potential was slightly different among cell lines. In A549 cells, the $\mathrm{IC}_{50}$ values were $3.2 \mu \mathrm{M}$ with treatment for $48 \mathrm{~h}$ and 3.3 $\mu \mathrm{M}$ with treatment for $72 \mathrm{~h}$. In $\mathrm{H} 1299$ cells, the $\mathrm{IC}_{50}$ values were 1.1 and $0.7 \mu \mathrm{M}$ with treatment for 48 and $72 \mathrm{~h}$, respectively. In the MCF-7 cell line, the $\mathrm{IC}_{50}$ values were $3.1 \mu \mathrm{M}$ with treatment for $48 \mathrm{~h}$ and $0.8 \mu \mathrm{M}$ with treatment for $72 \mathrm{~h}$. The $\mathrm{IC}_{50}$ values were 3.3 and $0.6 \mu \mathrm{M}$ for the HepG2 cell line with treatment for 48 and $72 \mathrm{~h}$, respectively. However, the HLF cell lines did not show significant growth inhibition with $\mathrm{ZM}$ up to $10 \mu \mathrm{M}$ for $72 \mathrm{~h}$. The results of

A

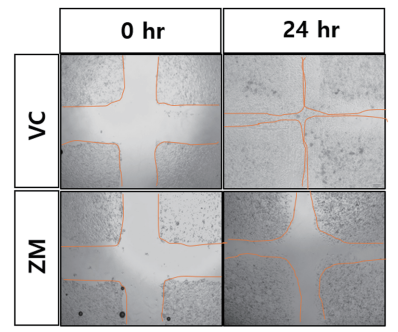

B

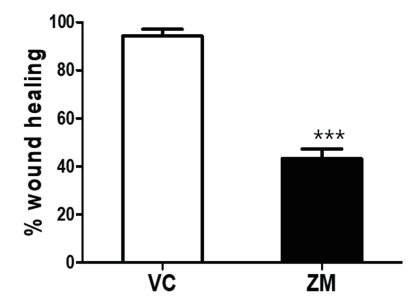

Fig. 3. Wound healing assay on ZM447439 (ZM) treated A549 cells. Wound healing assay was performed to assess the effect of ZM on the migration of A549 cells. (A) The representative images for the cells treated with $0.1 \%$ dimethyl sulfoxide (vehicle control, VC) or $10 \mu \mathrm{M} \mathrm{ZM}$ at 0 and 24 hours post-scratch are shown. (B) Quantification of the wound healing assay by migration area and \% wound healing of the initial scratch area was compared. Data are presented as mean \pm standard deviation and compared by t-test (each $n=3$ ). ${ }^{* *} p<0.001$ compared with VC. cell viability assays with $\mathrm{IC}_{50}$ doses are presented in Fig. 1. These data suggest that ZM has greater cytotoxicity against cancer cells than normal cells.

\section{Effects of ZM on invasion of A549 cells}

The invasion assay is widely used to study cell behavior and assess the metastatic potential of tumor cells. The Transwell invasion assay with Matrigel is one of the most widely used and convenient techniques to study cell invasion. To evaluate its effects on invasive activity, A549 cells were incubated for 24, 48, or $72 \mathrm{~h}$ with $\mathrm{ZM}$ at a concentration of $0.1,1$, or $10 \mu \mathrm{M}$. The invasive activity determined by counting the cells crossing the membrane pores was decreased by ZM in a dose- and time-dependent manner (Fig. 2). Cell invasion was significantly inhibited by ZM in a dose- and time-dependent manner. At the highest dose tested (10 $\mu \mathrm{M})$ for 24,48 , and $72 \mathrm{~h}, \mathrm{ZM}$ reduced invasion of A549 cells by $23.9 \pm 1 \%, 42 \pm 1.7 \%$ and $90.6 \pm 2.7 \%$, respectively (Fig. $2 \mathrm{~B}$, each $\mathrm{n}$ $=3$ ).

\section{Effects of ZM on migration of A549 cells}

A549 cells were grown to confluent monolayers, which were wounded by scratching with a pipette tip and incubated with ZM at a concentration of $3 \mu \mathrm{M}$. The cells in the DMSO-treated control group continuously migrated into, and almost completely closed, the scratch within 24 hours. The mean percentage of wound healing was $94.3 \pm 2.9 \%$ in three repeated experiments (Fig. 3). On the other hand, the migration ability of cells in the ZM-treated group
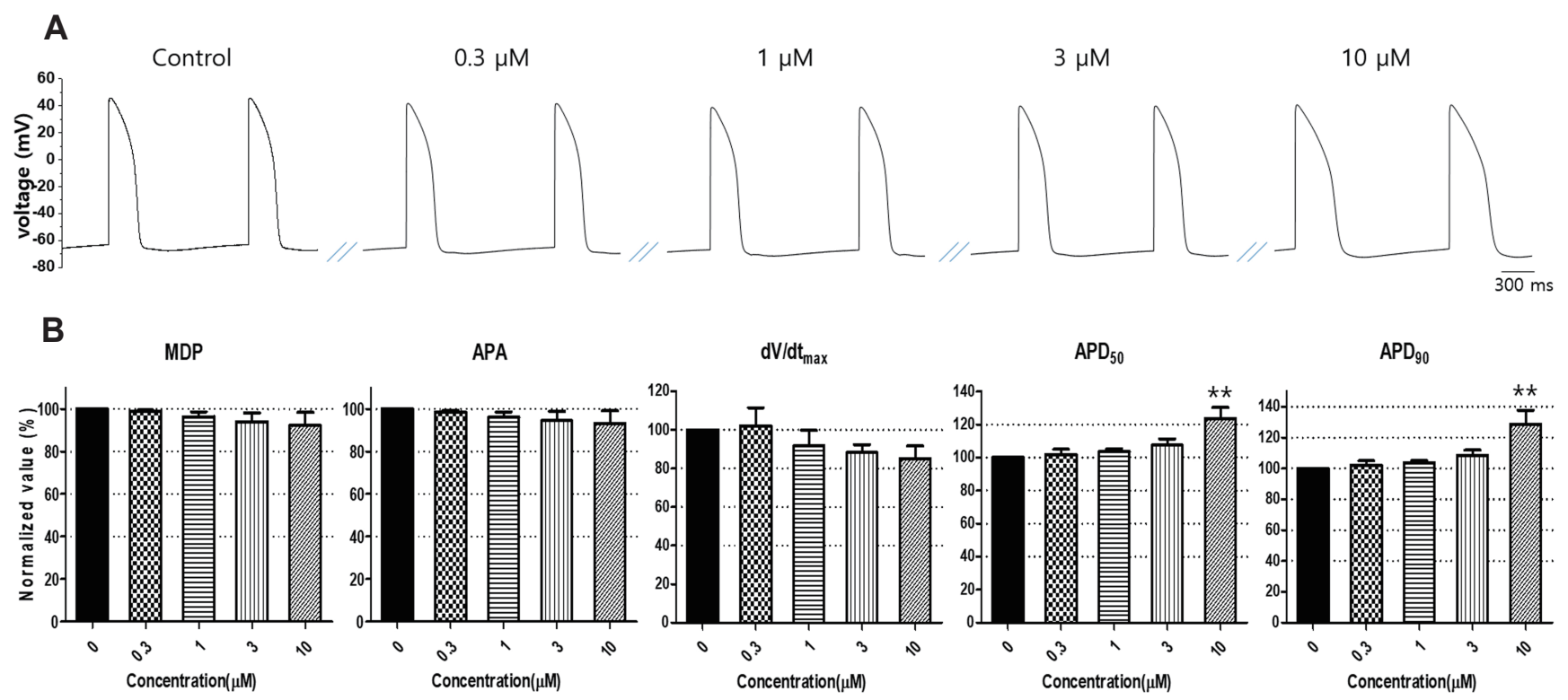

Fig. 4. Effects of ZM447439 (ZM) on action potential (AP) parameters of human induced pluripotent stem cell-derived cardiomyocytes (hiPSC-CMs). (A) Representative action potential traces of hiPSC-CMs in the absence (control) and presence of 0.3, 1, 3, and $10 \mu \mathrm{M} Z \mathrm{ZM}$. (B) Normalized AP parameters of hiPSC-CMs in control $(0 \mu \mathrm{M})$ and in the presence of $0.3,1,3$, and $10 \mu \mathrm{M} Z \mathrm{ZM}$. Data are expressed as mean \pm standard error of the mean and compared by ANOVA followed by Dunnett's test. MDP, maximal diastolic potential; APA, action potential amplitude; $\mathrm{dV} / \mathrm{dt}_{\text {max }}$ maximum upstroke velocity; $\mathrm{APD}_{50}$ or $\mathrm{APD}_{90}$, action potential duration at $50 \%$ or $90 \%$ repolarization. ${ }^{* *} \mathrm{p}<0.01$ compared to control $(\mathrm{n}=3)$. 
was significantly inhibited and they showed only $43.2 \pm 4.0 \%$ wound healing (Fig. 3B, each $n=3$ ).

\section{Effects of ZM on cardiac action potential of hiPSC- CMs}

To confirm the effects of ZM on the action potential (AP) of hiPSC-CMs, we measured the spontaneous APs in contracting cells using the whole-cell patch-clamp technique. Most cells showed ventricular-type APs with relatively more negative maximal diastolic potential (MDP) and rapid AP upstroke, with a long plateau phase and $\mathrm{AP}$ duration at $90 \%\left(\mathrm{APD}_{90}\right)$ longer than 200 ms. The MDP, maximum upstroke velocity $\left(\mathrm{dV} / \mathrm{dt}_{\max }\right), \mathrm{AP}$ amplitude (APA), AP duration at $50 \%\left(\mathrm{APD}_{50}\right)$ and $\mathrm{APD}_{90}$ values were analyzed; only ventricular-type cells were included in the analysis of the effects of ZM. Under control conditions, the values of the AP parameters were as follows: $-66.6 \pm 0.8 \mathrm{mV}$ for MDP, $99.9 \pm$ $6.8 \mathrm{~V} / \mathrm{s}$ for $\mathrm{dV} / \mathrm{dt}_{\max }, 258.4 \pm 17.2 \mathrm{~ms}$ for $\mathrm{APD}_{90}, 215.1 \pm 17.4 \mathrm{~ms}$ for $\mathrm{APD}_{50}$ and $113.3 \pm 1.9 \mathrm{mV}$ for APA $(\mathrm{n}=3$, mean $\pm \mathrm{SEM})$. The effects of $\mathrm{ZM}$ on the AP parameters were normalized relative to the control value in each cell and summarised in bar graphs (Fig. 4). Both $\mathrm{APD}_{50}$ and $\mathrm{APD}_{90}$ were significantly prolonged at $10 \mu \mathrm{M}$ $\mathrm{ZM}$ versus the other concentrations $(\mathrm{n}=3)$. At concentrations up to $10 \mu \mathrm{M}, \mathrm{ZM}$ did not affect any other AP parameters (MDP, dV/ $\mathrm{dt}_{\text {max }}$ or $\left.\mathrm{APA}\right)$. The $\mathrm{APD}_{50}$ and $\mathrm{APD}_{90}$ prolongation induced by ZM showed partial recovery after drug washout.

\section{Effects of ZM on cardiac ion channels}

The effects of ZM on cardiac ion channels were evaluated using the whole-cell patch-clamp technique. We measured the peak current amplitude and inhibitory percentage for various concentrations of ZM. In the studies of cardiac ion channels, ZM did not significantly affect $I_{\mathrm{Ks}}, I_{\mathrm{K} 1}, I_{\mathrm{Na}}$ or $I_{\mathrm{Ca}}$, but reduced $I_{\mathrm{hERG}}$ in a dosedependent manner. As shown in Fig. 5A, ZM dose-dependently decreased hERG tail current at $0.3,1,3$, and $10 \mu \mathrm{M}$ by $11.1 \%$,

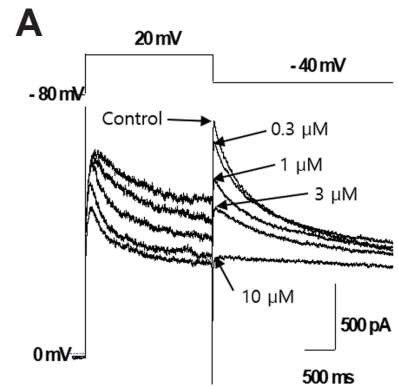

C
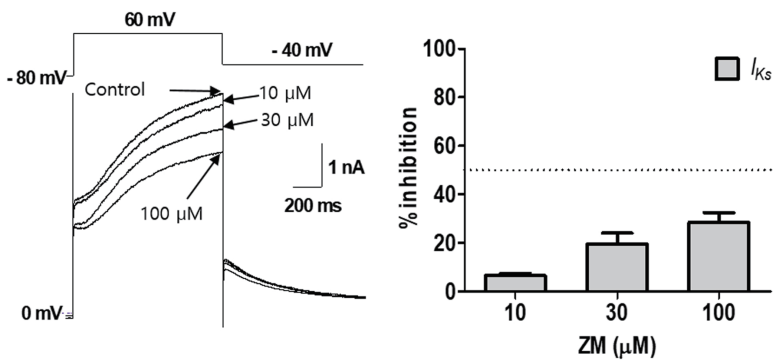

E

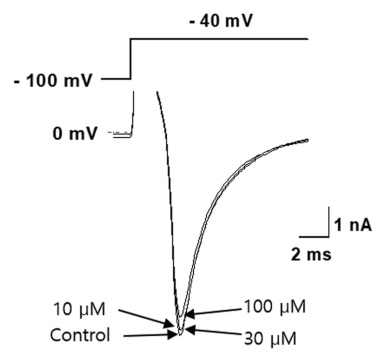

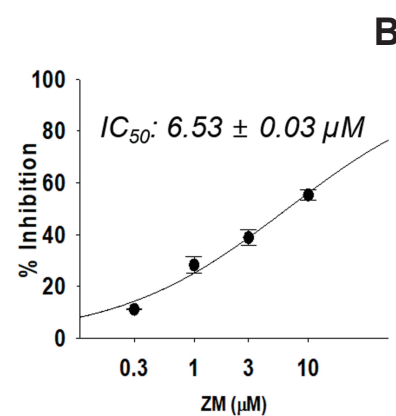

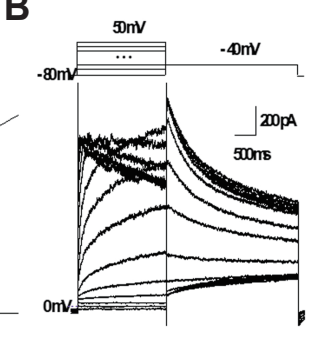

D
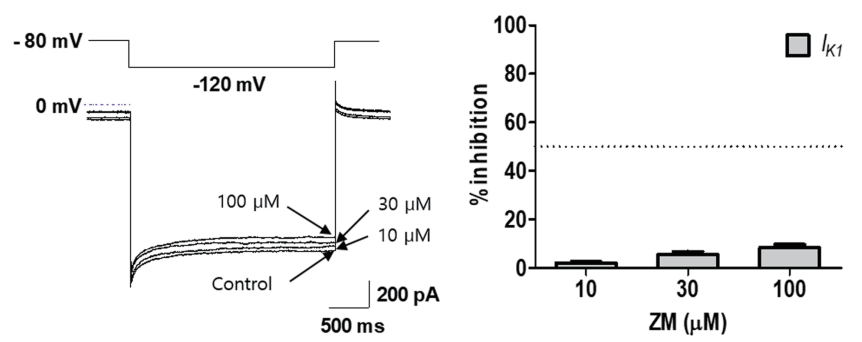

$\mathbf{F}$

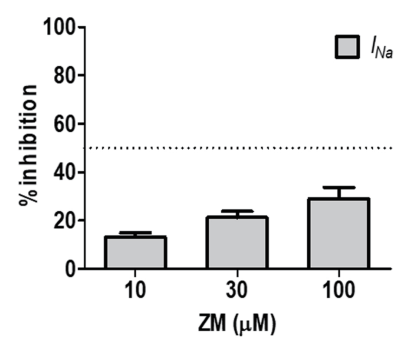

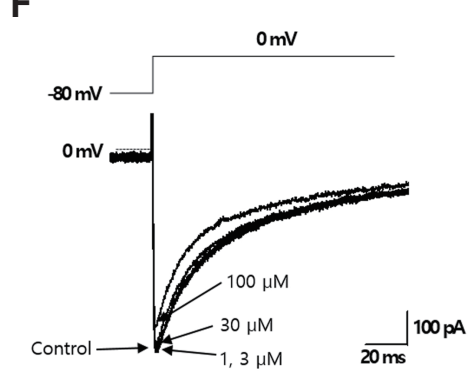

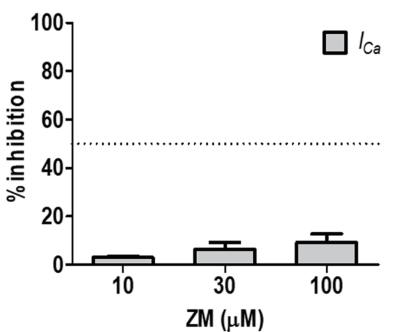

Fig. 5. Effects of ZM447439 (ZM) on cardiac ion channel currents. (A) Representative traces demonstrating the effect of ZM on $I_{\text {hERG }}$ at doses of 0.3 , 1,3 , and $10 \mu \mathrm{M}$, respectively (left). Dose-response relationship of ZM showing an $I_{50}$ value for $I_{\text {hERG }}$ (mean \pm standard error of the mean $[S E M], n=4$ ) (right). (B) The representative I-V traces of $\mathrm{I}_{\mathrm{hERG}}$ in control (left) and in the presence of $10 \mu \mathrm{M} \mathrm{ZM}$ (bottom). I-V relationships of $I_{\text {hERG }}$ in the control and 10 $\mu \mathrm{M} Z \mathrm{ZM}$ (mean $\pm \mathrm{SEM}, \mathrm{n}=3$ ) (right). (C-F) Representative traces demonstrating the effect of ZM on $I_{\mathrm{Ks}}(\mathrm{C}), I_{\mathrm{K} 1}(\mathrm{D}), I_{\mathrm{Na}}(\mathrm{E})$ and $I_{\mathrm{Ca}}(\mathrm{F})$ at doses of 10,30 , and $100 \mu \mathrm{M}$, respectively (each left) and dose-response relationship of ZM for each ion currents (mean $\pm \mathrm{SEM}, \mathrm{n}=3$ ) (each right). 
$28.3 \%, 38.9 \%$, and $55.4 \%$, respectively, with an $\mathrm{IC}_{50}$ for $I_{\text {hERG }}$ of $6.53 \pm 0.03 \mu \mathrm{M}(\mathrm{n}=4)$. The $\mathrm{IC}_{50}$ values for $I_{\mathrm{Ks}}, I_{\mathrm{K} 1}, I_{\mathrm{Na}}$, and $I_{\mathrm{Ca}}$ were around $100 \mu \mathrm{M}$ (Fig. 5C-F).

\section{Effects of ZM on cardiac contraction}

Before testing ZM, we have tested a positive control drug as representative negative inotropes, nifedipine, extensively to confirm the assay reliability. As shown to Fig. 6A, nifedipine produced a concentration-dependent decrease in sarcomere shortening, contraction velocity and relaxation velocity. However, ZM did not significantly affect these parameters of contractility (Fig. $6 \mathrm{~B})$. Mean and SEM values for parameters of contraction/relaxation were summarized in Table 1.

\section{DISCUSSION}

The AKs are only expressed and active during mitosis $[19,20]$. Therefore, non-proliferating healthy cells would be less adversely affected by AK inhibitors than proliferating cancer cells. Consistent with previous studies, we confirmed that proliferating A549, H1299, MCF-7 and HepG2 tumor cells were killed by treatment with $\mathrm{ZM}$, with $\mathrm{IC}_{50}$ values in the submicromolar range, while this agent showed little effect on normal HLF cells (Fig. 1). Evidence has shown that ZM has different effects in tumorous and normal cells, such as proliferating epithelial cells of the oral and gut mucosa, according to the presence or absence of the p53-mediated post-mitotic checkpoint $[20,21]$. These tumor cells underwent additional cycles with aberrant mitosis and failure of cytokinesis, which would be predicted to result in cell death. In addition to the cytotoxicity of ZM, this agent also inhibited the invasion and

A

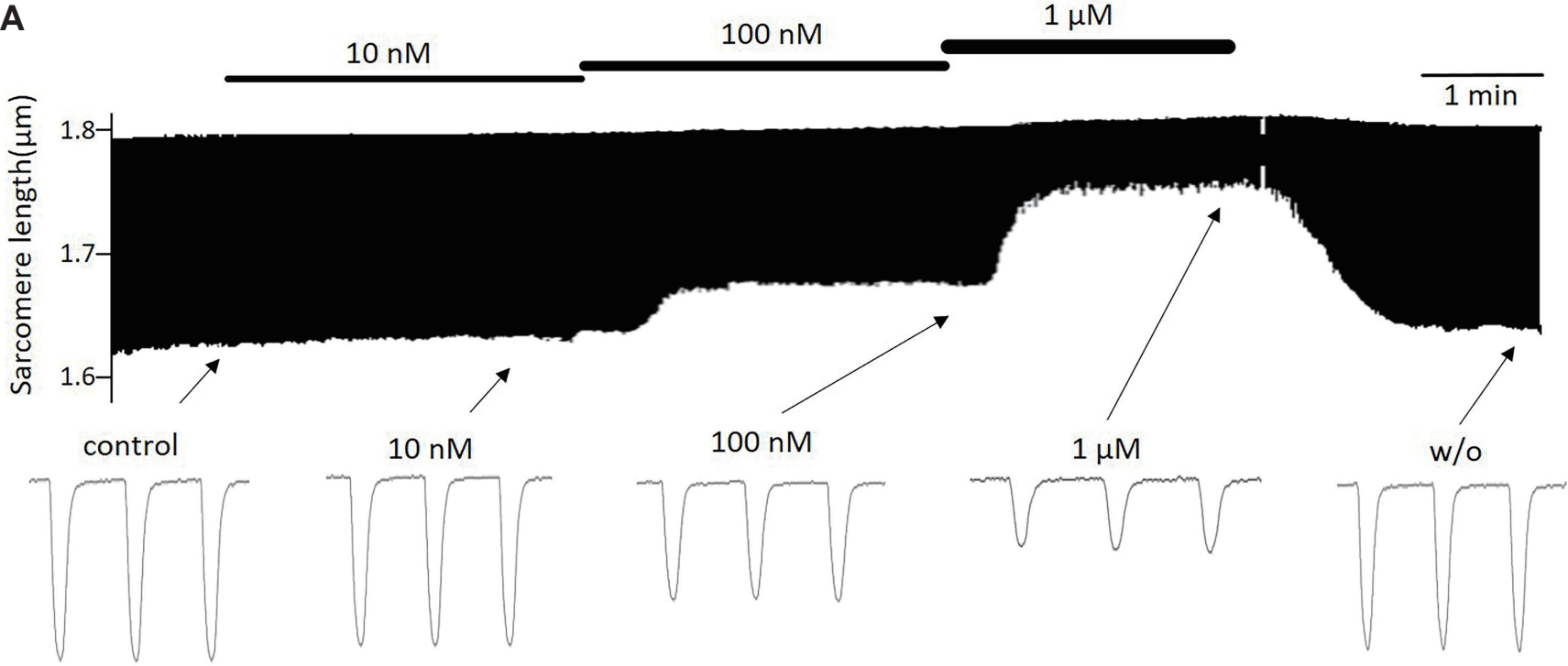

B

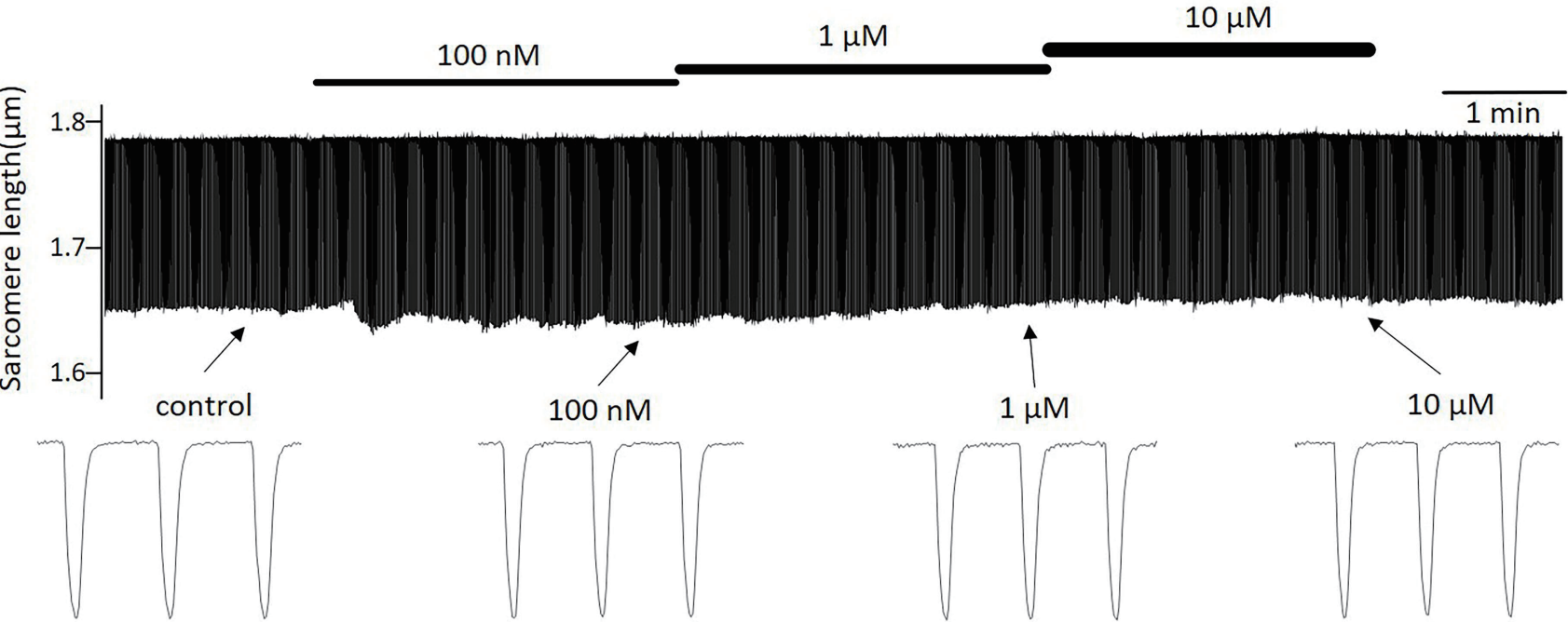

Fig. 6. Effects of ZM447439 (ZM) on contraction of rat ventricular myocyte. (A) Representative raw traces of sarcomere shortening and lengthening in the absence (control) and presence of $10 \mathrm{nM}, 100 \mathrm{nM}$, and $1 \mu \mathrm{M}$ nifedipine. (B) Typical raw traces of sarcomere shortening/lengthening in control and the presence of $\mathrm{ZM}$ at concentrations of $100 \mathrm{nM}, 1 \mu \mathrm{M}$, and $10 \mu \mathrm{M}$. 
Table 1. Effects of nifedipine and ZM on the parameters for myocyte contraction

\begin{tabular}{|c|c|c|c|c|c|}
\hline Variable & Control & $10 \mathrm{nM}$ & $100 \mathrm{nM}$ & $1 \mu \mathrm{M}$ & $10 \mu \mathrm{M}$ \\
\hline \multicolumn{6}{|l|}{ Nifedipine } \\
\hline Sarcomere length $(\mu \mathrm{m})$ & $1.89 \pm 0.04$ & $1.89 \pm 0.04$ & $1.87 \pm 0.05$ & $1.87 \pm 0.06$ & \\
\hline Sarcomere shortening $(\mu \mathrm{m})$ & $0.20 \pm 0.004$ & $0.21 \pm 0.004$ & $0.13 \pm 0.012^{* * *}$ & $0.06 \pm 0.008^{* * *}$ & \\
\hline Contraction velocity $(\mu \mathrm{m} / \mathrm{s})$ & $5.81 \pm 0.06$ & $5.37 \pm 0.11^{* *}$ & $2.11 \pm 0.06^{* * *}$ & $1.38 \pm 0.04^{* * *}$ & \\
\hline Relaxation velocity $(\mu \mathrm{m} / \mathrm{s})$ & $4.28 \pm 0.09$ & $4.05 \pm 0.08$ & $2.56 \pm 0.07^{* * *}$ & $0.94 \pm 0.03^{* * *}$ & \\
\hline \multicolumn{6}{|l|}{ ZM } \\
\hline Sarcomere length $(\mu \mathrm{m})$ & $1.80 \pm 0.03$ & & $1.84 \pm 0.03$ & $1.78 \pm 0.03$ & $1.80 \pm 0.03$ \\
\hline Sarcomere shortening $(\mu \mathrm{m})$ & $0.16 \pm 0.003$ & & $0.17 \pm 0.006$ & $0.16 \pm 0.003$ & $0.16 \pm 0.003$ \\
\hline Contraction velocity $(\mu \mathrm{m} / \mathrm{s})$ & $4.82 \pm 0.09$ & & $4.92 \pm 0.09$ & $4.77 \pm 0.09$ & $4.82 \pm 0.09$ \\
\hline Relaxation velocity $(\mu \mathrm{m} / \mathrm{s})$ & $3.47 \pm 0.07$ & & $3.71 \pm 0.07$ & $3.53 \pm 0.07$ & $3.81 \pm 0.13$ \\
\hline
\end{tabular}

Values are presented as mean \pm standard error of the mean $(\mathrm{n}=4$ for nifedipine, $\mathrm{n}=3$ for ZM447439 [ZM]), **p $<0.01, * * * \mathrm{p}<0.001$ compared to control, Dunnett's test.

migration of A549 cells (Figs. 2 and 3). This in vitro efficacy suggested that ZM could be a potent anti-cancer chemotherapeutic drug.

One of the major concerns in drug development is drug-induced cardiotoxicity. Indeed, many drugs, including anti-cancer drugs, have been shown to induce fetal arrhythmia and death. In this study, we conducted several in vitro assays to examine ZMinduced cardiotoxicity with hiPSC-CMs, which are considered a suitable screening model for drugs that could be used in humans. In addition, to evaluate the potential effects of ZM on cardiac repolarisation, whole-cell patch-clamp experiments were performed using cells with heterogeneous cardiac ion channel expression for depolarizing $I_{\mathrm{Na}}, I_{\mathrm{Ca}}$ and repolarizing $I_{\mathrm{hERG}}, I_{\mathrm{Ks}}$, and $I_{\mathrm{K} 1}$. The results indicated that at the highest concentration tested in this study, i.e., $10 \mu \mathrm{M}$, ZM induced prolongation of APD due to hERG channel inhibition. However, ZM at any of the other test concentrations, i.e., from $0.1 \mu \mathrm{M}$ to $3 \mu \mathrm{M}$, did not significantly affect AP parameters or cardiac ion channel currents (Figs. 4 and 5).

The use of stem cell technology is a promising approach for drug screening due to hiPSCs enable to overcome the species differences and to have the potential for high-throughput screening of drugs in vitro [22,23]. The results for the effects of $\mathrm{ZM}$ on cardiac AP in hiPSC-CMs and ion channel assay show that hiPSC-CMs recapitulate the electrophysiological effects of $\mathrm{ZM}$ on cardiac ion channels. These results improve the insight into the usefulness of hiPSC-CMs as a new human-based model for AKIsrelated drug safety assessment.

We also conducted contractility assays with rat ventricular myocytes, and the results showed that ZM did not significantly affect myocardial contraction/relaxation at concentrations up to $10 \mu \mathrm{M}$ (Fig. 6), consistent with the results of ion channel assay using $\mathrm{Ca}_{\mathrm{v}}$ 1.2-expressing $\mathrm{CHO}$ cells (Fig. 5E). Intracellular calcium plays a key role in excitation-contraction coupling of heart and has important functional interactions with other cations including sodium, potassium, and magnesium, etc. Calcium transients associated with contraction-relaxation cycles of the heart [24]. Intracellular calcium is regulated by transport proteins and ion channels. Among them, $I_{\mathrm{Ca}}$ is one of the major sources of calcium influx [25]. Because the balance between $I_{\mathrm{Ca}}$ and $I_{\mathrm{K}}\left(I_{\mathrm{Kr}}\right.$ and $\left.I_{\mathrm{Ks}}\right)$ determines the amplitude and duration of the plateau phase of cardiac AP, pharmacological inhibition of the associated ion channels has been a critical issue of cardiac toxicity [26]. Fortunately, these studies for the effects of $\mathrm{ZM}$ on $I_{\mathrm{Ca}}$ and contractility of rVMs suggest that ZM did not have adverse effects on the cardiac calcium currents and contractility up to $10 \mu \mathrm{M}$.

In this study, ZM dose-dependently decreased hERG tail current with an $\mathrm{IC}_{50}$ for $I_{\mathrm{hERG}}$ of $6.53 \pm 0.03 \mu \mathrm{M}$ which is higher compared to effective doses to kill the tumorous cells ranging from 0.6 $\mu \mathrm{M}$ to $3.3 \mu \mathrm{M}$ in this study. In addition, ZM did not significantly affect myocardial contraction/relaxation and any other ion channel currents, $I_{\mathrm{Ks}}, I_{\mathrm{K} 1}, I_{\mathrm{Na}}$ or $I_{\mathrm{Ca}}$ at concentrations up to $10 \mu \mathrm{M}$. The most common mechanism of drug-induced QT prolongation and associated ventricular arrhythmias involves blockade of the $I_{\mathrm{Kr}}$ [27]. As the hERG gene encodes the pore-forming subunit of the $I_{\mathrm{Kr}}$ channel, blockade of hERG channels could result in APD and QT prolongation [28]. However, as with QT prolongation, hERG inhibition is also a known risk factor, and it is widely accepted that hERG inhibition is neither absolutely necessary nor sufficient for a drug to increase the risk of torsadogenesis [29]. Short QT syndrome (SQTS) is a rare disease associated with short QT intervals and increased risk for atrial and ventricular fibrillation [30]. A gain-of-function mutation in KCNH2 (hERG) is linked to SQTS type 1 (SQT1). A gain-of-function mutation on $\mathrm{KCNH} 2$ causes a significant increase of $I_{\mathrm{Kr}}$ during the action potential plateau. For cancer patients with SQTS, ZM could be a primary chemotherapeutic agent.

In summary, ZM showed potent broad-spectrum anti-tumor activity, but relatively low levels of cardiac side effects compared to the effective doses to tumor. Therefore, ZM has a potential to be a candidate as an anticancer with low cardiac toxicity. 


\section{ACKNOWLEDGEMENTS}

This work was supported by the Technology Innovation Program funded by the Ministry of Trade, Industry and Energy of Republic of Korea (10067737 [K.S.K.]). In addition, this research was also supported by the Basic Science Research Program funded by the Ministry of Education (NRF-2018R1D1A1B07047733 [H.A.L.]).

\section{CONFLICTS OF INTEREST}

The authors declare no conflicts of interest.

\section{REFERENCES}

1. Cirak Y, Furuncuoglu Y, Yapicier O, Aksu A, Cubukcu E. Aurora A overexpression in breast cancer patients induces taxane resistance and results in worse prognosis. J BUON. 2015;20:1414-1419.

2. Zhang Y, Jiang C, Li H, Lv F, Li X, Qian X, Fu L, Xu B, Guo X. Elevated Aurora $\mathrm{B}$ expression contributes to chemoresistance and poor prognosis in breast cancer. Int J Clin Exp Pathol. 2015;8:751-757.

3. Zekri A, Lesan V, Ghaffari SH, Tabrizi MH, Modarressi MH. Gene amplification and overexpression of Aurora-C in breast and prostate cancer cell lines. Oncol Res. 2012;20:241-250.

4. Yang H, Ou CC, Feldman RI, Nicosia SV, Kruk PA, Cheng JQ. Aurora-A kinase regulates telomerase activity through c-Myc in human ovarian and breast epithelial cells. Cancer Res. 2004;64:463467.

5. Gavriilidis P, Giakoustidis A, Giakoustidis D. Aurora kinases and potential medical applications of aurora kinase inhibitors: a review. J Clin Med Res. 2015;7:742-751.

6. Sasai K, Katayama H, Stenoien DL, Fujii S, Honda R, Kimura M, Okano Y, Tatsuka M, Suzuki F, Nigg EA, Earnshaw WC, Brinkley WR, Sen S. Aurora-C kinase is a novel chromosomal passenger protein that can complement Aurora-B kinase function in mitotic cells. Cell Motil Cytoskeleton. 2004;59:249-263.

7. Yan X, Cao L, Li Q, Wu Y, Zhang H, Saiyin H, Liu X, Zhang X, Shi Q, Yu L. Aurora $C$ is directly associated with Survivin and required for cytokinesis. Genes Cells. 2005;10:617-626.

8. Ditchfield C, Johnson VL, Tighe A, Ellston R, Haworth C, Johnson T, Mortlock A, Keen N, Taylor SS. Aurora B couples chromosome alignment with anaphase by targeting BubR1, Mad2, and Cenp-E to kinetochores. JCell Biol. 2003;161:267-280.

9. Woo JK, Kang JH, Shin D, Park SH, Kang K, Nho CW, Seong JK, Lee SJ, Oh SH. Daurinol enhances the efficacy of radiotherapy in lung cancer via suppression of aurora kinase A/B expression. Mol Cancer Ther. 2015;14:1693-1704.

10. Ding YH, Zhou ZW, Ha CF, Zhang XY, Pan ST, He ZX, Edelman JL, Wang D, Yang YX, Zhang X, Duan W, Yang T, Qiu JX, Zhou SF. Alisertib, an Aurora kinase A inhibitor, induces apoptosis and autophagy but inhibits epithelial to mesenchymal transition in human epithelial ovarian cancer cells. Drug Des Devel Ther. 2015;9:425464.
11. Min YH, Kim W, Kim JE. The Aurora kinase A inhibitor TC-A2317 disrupts mitotic progression and inhibits cancer cell proliferation. Oncotarget. 2016;7:84718-84735.

12. Li M, Jung A, Ganswindt U, Marini P, Friedl A, Daniel PT, Lauber K, Jendrossek V, Belka C. Aurora kinase inhibitor ZM447439 induces apoptosis via mitochondrial pathways. Biochem Pharmacol. 2010;79:122-129.

13. Force T, Krause DS, Van Etten RA. Molecular mechanisms of cardiotoxicity of tyrosine kinase inhibition. Nat Rev Cancer. 2007;7:332-344.

14. Schmidinger M, Zielinski CC, Vogl UM, Bojic A, Bojic M, Schukro C, Ruhsam M, Hejna M, Schmidinger H. Cardiac toxicity of sunitinib and sorafenib in patients with metastatic renal cell carcinoma. J Clin Oncol. 2008;26:5204-5212.

15. Sereno M, Brunello A, Chiappori A, Barriuso J, Casado E, Belda C, de Castro J, Feliu J, González-Barón M. Cardiac toxicity: old and new issues in anti-cancer drugs. Clin Transl Oncol. 2008;10:35-46.

16. Ewer MS, Ewer SM. Cardiotoxicity of anticancer treatments. Nat Rev Cardiol. 2015;12:547-558.

17. Curigliano G, Cardinale D, Dent S, Criscitiello C, Aseyev O, Lenihan D, Cipolla CM. Cardiotoxicity of anticancer treatments: Epidemiology, detection, and management. CA Cancer J Clin. 2016;66:309-325.

18. Peroukides S, Alexopoulos A, Kalofonos H, Papadaki H. Cardiovascular effects of treatment with taxanes. J Cardiovasc Med (Hagerstown). 2012;13:319-324.

19. Willems E, Dedobbeleer M, Digregorio M, Lombard A, Lumapat PN, Rogister B. The functional diversity of Aurora kinases: a comprehensive review. Cell Div. 2018;13:7.

20. Walter AO, Seghezzi W, Korver W, Sheung J, Lees E. The mitotic serine/threonine kinase Aurora2/AIK is regulated by phosphorylation and degradation. Oncogene. 2000;19:4906-4916.

21. Margolis RL, Lohez OD, Andreassen PR. G1 tetraploidy checkpoint and the suppression of tumorigenesis. J Cell Biochem. 2003;88:673683.

22. Sinnecker D, Laugwitz KL, Moretti A. Induced pluripotent stem cell-derived cardiomyocytes for drug development and toxicity testing. Pharmacol Ther. 2014;143:246-252.

23. Lynch S, Pridgeon CS, Duckworth CA, Sharma P, Park BK, Goldring CEP. Stem cell models as an in vitro model for predictive toxicology. Biochem J. 2019;476:1149-1158.

24. Morgan JP, Morgan KG. Calcium and cardiovascular function. Intracellular calcium levels during contraction and relaxation of mammalian cardiac and vascular smooth muscle as detected with aequorin. Am J Med. 1984;77(5A):33-46.

25. Bodi I, Mikala G, Koch SE, Akhter SA, Schwartz A. The L-type calcium channel in the heart: the beat goes on. J Clin Invest. 2005;115:3306-3317.

26. Mladěnka P, Applová L, Patočka J, Costa VM, Remiao F, Pourová J, Mladěnka A, Karlíčková J, Jahodář L, Vopršalová M, Varner KJ, Štěrba M. Comprehensive review of cardiovascular toxicity of drugs and related agents. Med Res Rev. 2018;38:1332-1403.

27. Sanguinetti MC, Tristani-Firouzi M. hERG potassium channels and cardiac arrhythmia. Nature. 2006;440:463-469.

28. Roden DM. Drug-induced prolongation of the QT interval. N Engl JMed. 2004;350:1013-1022.

29. Li Z, Dutta S, Sheng J, Tran PN, Wu W, Chang K, Mdluli T, Strauss 
DG, Colatsky T. Improving the in silico assessment of proarrhythmia risk by combining hERG (Human Ether-à-go-go-Related Gene) channel-drug binding kinetics and multichannel pharmacology. Circ Arrhythm Electrophysiol. 2017;10:e004628.

30. Brugada R, Hong K, Dumaine R, Cordeiro J, Gaita F, Borggrefe M,
Menendez TM, Brugada J, Pollevick GD, Wolpert C, Burashnikov E, Matsuo K, Wu YS, Guerchicoff A, Bianchi F, Giustetto C, Schimpf R, Brugada P, Antzelevitch C. Sudden death associated with short-QT syndrome linked to mutations in HERG. Circulation. 2004;109:3035. 